\title{
Recombinant Platelet-derived Growth Factor B Gene Expression in Porcine Arteries Induces Intimal Hyperplasia In Vivo
}

\author{
Elizabeth G. Nabel, * Zhiyong Yang, * Susanne Liptay, “ Hong San, David Gordon, * Christian C. Haudenschild, \\ and Gary J. Nabel * \\ * Departments of Internal Medicine, Biological Chemistry, and Pathology, Howard Hughes Medical Institute, University of \\ Michigan, Ann Arbor, Michigan 48109; and ${ }^{\ddagger}$ Jerome H. Holland Laboratory, American Red Cross, Rockville, Maryland 20855
}

\begin{abstract}
Platelet-derived growth factor (PDGF) B chain induces cell proliferation in vitro and is associated with arterial lesions that cause cardiovascular disease. However, it has been difficult to document the biological response to PDGF B gene expression in arteries in vivo. To determine the biologic effects of this growth factor in vivo, we have introduced an eukaryotic expression vector plasmid encoding recombinant PDGF $B$ by direct gene transfer into porcine iliofemoral arteries using DNA liposome complexes. The presence of PDGF B plasmid DNA and expression of recombinant mRNA were confirmed by polymerase chain reaction analysis, and recombinant PDGF protein was demonstrated by immunohistochemistry. Intimal thickening was observed in porcine arteries 21 days following transfection with the recombinant PDGF B gene compared with arteries transduced with a control gene, $E$. coli $\beta$-galactosidase. An eightfold increase in intimal to medial ratio was present in PDGF B gene transfected arteries compared with control transfected arteries $(P=0.001)$. This study suggests that expression of a recombinant PDGF $B$ gene in vivo can play a role in the induction of intimal hyperplasia, which can lead to cardiovascular diseases. (J. Clin. Invest. 1993. 91:1822-1829.) Key words: gene transfer • gene expression • platelet-derived growth factor $\cdot$ cellular proliferation $\cdot$ liposomes
\end{abstract}

\section{Introduction}

Multiple growth factors stimulate vascular smooth muscle cell proliferation in vitro, including the dimeric forms of PDGF. PDGF BB is a potent smooth muscle cell mitogen $(1,2)$ that may also act as a smooth muscle chemoattractant (3-5). In vivo, the role of the PDGF $B$ gene in tissue injury and atherosclerosis has been difficult to address. This difficulty arises from the complexity of cellular and protein interactions in

Send correspondence and reprint requests to Elizabeth G. Nabel, M.D., University of Michigan, MSRB II, Room 3560, 1150 W. Medical Center Drive, Ann Arbor, MI 48109-0688.

Received for publication 17 July 1992 and in revised form 23 December 1992.

J. Clin. Invest.

(c) The American Society for Clinical Investigation, Inc. 0021-9738/93/04/1822/08 $\$ 2.00$

Volume 91, April 1993, 1822-1829 vivo, their paracrine and autocrine nature, and the cascade of events that can be induced by experimental manipulations. It is often difficult to determine whether a specific gene product induces intimal hyperplasia directly or indirectly through other gene products synthesized in response to injury. Recently, it has become possible to express recombinant genes in vivo by direct gene transfer utilizing retroviral vectors or DNA liposome complexes (6-9). Direct gene transfer permits the delivery of a specific recombinant gene into vascular cells at specific sites in vivo and affords the opportunity to determine the effects of a specific gene product in the arterial wall (10). To define the function of PDGF B within arteries, we have directly introduced the recombinant gene in porcine arteries in vivo and have shown that expression of recombinant PDGF B can cause intimal hyperplasia. These data suggest that expression of PDGF B can induce vascular lesions relevant to the pathogenesis of atherosclerosis and restenosis.

\section{Methods}

Plasmids and cell transfection. The PDGF B expression vector used for in vitro and in vivo experiments was prepared by ligating the SallXbal fragment of the $\mathrm{v}$-sis gene into the Xhol- BamH1 cloning site of the pSVL vector (11) (Pharmacia, LKB Biotechnology, Piscataway, $\mathrm{NJ})$. This vector utilizes the SV40 late promoter to regulate expression of the PDGF B gene. Primary porcine endothelial cell cultures were established as previously described (12) to test expression of the PDGF $B$ vector. The $\mathrm{pSVL} / \mathrm{PDGF} \mathrm{B}$ plasmid expression vector was transfected into porcine endothelial cells using $12 \mu \mathrm{g}$ of Lipofectin ${ }^{\circledR}$ (Bethesda Research Laboratories, Gaithersburg, MD) and $5 \mu \mathrm{g}$ of DNA (stock concentration $>1 \mathrm{mg} / \mathrm{ml}$ ) (13). Culture transduced endothelial cells were assayed for secretion of recombinant PDGF BB supernatants (10\%) with a colorimetric proliferation assay (14) using NIH 3T3 cells, and a fourfold or greater increase in proliferative activity was observed. No evidence of cell transformation was observed in endothelial or vascular smooth muscle cells stably transduced with this vector. The E. coli $\beta$-galactosidase expression vector was prepared by cloning the $\beta$-galactosidase gene into the pDOL vector, which was derived from the Moloney murine leukemia virus (Mo-MuLV) (15). The wild type Mo-MuLV LTR provided the promoter for the $\beta$-galactosidase gene.

Gene transfer in vivo. In vivo arterial gene transfer was performed in 15 pigs, 9 with the recombinant PDGF B gene and 6 with a control reporter gene, E. coli $\beta$-galactosidase. Double balloon catheters were positioned in the iliofemoral arteries as previously described (6). The arterial segment was rinsed with $5 \mathrm{ml}$ saline and $5 \mathrm{ml}$ Opti-MEM to clear the vessel of blood. Approximately $10 \mathrm{~min}$ before the insertion of the catheter, the DNA liposome conjugates were prepared. $5 \mu$ l lipofectin was diluted into $0.2 \mathrm{ml}$ Opti-MEM at room temperature, and 2-5 $\mu \mathrm{g}$ plasmid DNA (stock concentration $>1 \mathrm{mg} / \mathrm{ml}$ ) was added and mixed by gentle tapping. The solution remained at room temperature for 5-10 min, and $0.5 \mathrm{ml}$ Opti-MEM was added to the DNA liposome 
solution. The solution was instilled into the arterial space between the two balloons at $150 \mathrm{mmHg}$, measured by a pressure transducer, and allowed to incubate for $20 \mathrm{~min}$. Following incubation, the catheter was removed and arterial circulation was restored. In all pigs, both the left and right iliac arteries were transfected. At the time of pigs' death, the iliofemoral arteries were fixed in situ under physiological distending pressures $(\sim 90 \mathrm{mmHg})$ with formalin or methyl Carnoy's solution (60\% methanol, $30 \%$ ethanol, $10 \%$ glacial acetic acid by volume percent) for $20 \mathrm{~min} .5$ pigs were killed at $1 \mathrm{wk}$ and 10 pigs were killed at 3 wk for DNA, mRNA, protein, and histology analysis. A 3-wk time point was selected since recombinant genes have been shown to be stably expressed in vascular cells at $2-3$ wks $(6,10)$ and any intimal thickening induced by arterial manipulation should be observed by this time point (16).

Polymerase chain reaction analysis. Recombinant PDGF gene transfer in arterial segments was analyzed by PCR of genomic DNA using 35 cycles of denaturation $\left(94^{\circ} \mathrm{C}, 1 \mathrm{~min}\right)$, annealing $\left(60^{\circ} \mathrm{C}, 2\right.$ $\min )$, and polymerization $\left(72^{\circ} \mathrm{C}, 1 \mathrm{~min}\right)$ as previously described (13). For PCR analysis of recombinant PDGF transfected vessels, primers were synthesized from the primate cDNA sequence (17), which was not homologous to porcine sequence and generated a 384-bp fragment: sense ( 25 mer): TAC TCC TCT TAA GCT GCG TAT TCG G; antisense (25 mer): ACA CCA GGA AGT TGG CAT TGG TGC G. The sense primer was selected from a region 50 bp upstream to the transcription start site. $\beta$-galactosidase primers were synthesized as follows: sense: TGG AGC GCC GAA ATC CCG AAT CTC TAT CGT; antisense TAG CCA GCG CGG ATC GGT CAG ACG ATT. Samples were analyzed by ethidium bromide staining on a $1 \%$ agarose gel.

Recombinant PDGF BB mRNA expression was analyzed by reverse transcriptase PCR. Arterial samples were obtained, and total cellular RNA was prepared by the guanidine method (18). Nucleic acids were extracted and treated with DNase I $\left(3 \mu \mathrm{l}, 10-50 \times 10^{4} \mathrm{U} / \mathrm{ml}\right)$ (RNase-free) (Boehringer Mannheim Biochemicals, Indianapolis, IN) in buffer ( $40 \mathrm{mM}$ Tris- $\mathrm{HCl}, \mathrm{pH} 7.9,10 \mathrm{mM} \mathrm{NaCl}, 6 \mathrm{mM} \mathrm{MgCl}_{2}, 0.1$ $\mathrm{mM} \mathrm{CaCl} 237^{\circ} \mathrm{C}$ for 30 min to eliminate contamination. The PCR analysis of mRNA was performed using 35 cycles of denaturation, annealing, and polymerization as described above. For RNA PCR, samples were analyzed in the presence and absence of reverse transcriptase, $15 \mathrm{U}$ (Promega Biotec, Madison, WI). Primers from the primate PDGF B cDNA sequence, as defined above, were used to generate a 384-bp fragment. Samples were analyzed by Southern blotting using standard methods (19).

Immunohistochemical analysis. Recombinant PDGF BB protein expression was analyzed by immunohistochemistry of artery segments transfected with the $\mathrm{E}$. coli $\beta$-galactosidase gene, the recombinant PDGF B gene, or balloon injured, nontransfected artery segments. Artery segments were fixed in methyl Carnoy's solution or formalin and embedded in paraffin. Specimens were sectioned $(6 \mu \mathrm{m})$, deparaffinized in three changes of xylene (National Diagnostics, Manville, $\mathrm{NJ}$ ), and rehydrated in $100 \%, 95 \%$, and $75 \%$ ethyl alcohol. Endogenous peroxidase was blocked by preincubation in $0.3 \% \mathrm{H}_{2} \mathrm{O}_{2}$ for $30 \mathrm{~min}$. Sections were incubated in PBS with 1\% BSA with a 1:100 dilution of a monoclonal mouse anti-human PDGF BB IgG $_{2 b}$ antibody (Promega Biotec) or a purified mouse $\mathrm{IgG}_{2 \mathrm{~b}}$ antibody (Promega Biotec), 1:400 dilution, for $60 \mathrm{~min}$. The monoclonal anti-human PDGF BB antibody primarily detects PDGF BB homodimer but potentially can stain human PDGF AB heterodimer and AA homodimer. Biotinylated rabbit anti-mouse $\mathrm{IgG}_{2}$ antibody (Zymed Labs, Inc., South San Francisco, CA), 1:400 dilution was added for $30 \mathrm{~min}$ at room temperature, and specimens were stained with streptavidin-horseradish peroxidase ( Vector Laboratories, Burlingame, CA) complex $(1: 5,000)$ for $30 \mathrm{~min}$ at room temperature, rinsed, incubated for $10 \mathrm{~min}$ at room temperature in diaminobenzidine substrate (Sigma Immunochemicals, Inc., St. Louis, MO) with $0.045 \%$ nickel chloride to produce a gray-black reaction product. Methyl green nuclear counterstaining was performed.

Macrophage staining was performed using a monoclonal $\operatorname{IgG}_{2 b}$ antibody to porcine macrophages and a nonspecific esterase stain. Methyl Carnoy's fixed, paraffin-embedded arteries and intestine were sec- tioned $(6 \mu \mathrm{m})$, deparaffinized, rehydrated and incubated overnight with a 1:100 dilution of a monoclonal IgG $_{2 b}$ antibody to porcine macrophages (ATCC HB 142.1; American Type Culture Collection, Rockville, $M D$ ) or purified mouse serum. Biotinylated anti-mouse immunoglobulin (Vector Laboratories) was then applied at a 1:200 dilution for $30 \mathrm{~min}$, followed by another 30-min incubation in Vectastain ABC-AP reagent (Vector Laboratories), and then developed with the alkaline phosphase substrate (Alkaline phosphatase substrate kit; Vector Laboratories), which produced a red reaction product. Methyl green nuclear counterstaining was performed as above.

For histochemical staining of macrophages, unfixed arteries, and spleen embedded in Tissue-Tek $B$ OCT embedding compound (Miles Ames Division, Inc., Elkart, IN) were sectioned $(6 \mu \mathrm{m})$, fixed in citrate-acetone-formaldehyde solution, and stained in PBS with $1 \%$ sodium nitrate, $1 \%$ pararosaniline and $10 \%$ alpha naphthyl butyrate (Sigma Immunochemicals) for $1 \mathrm{~h}$ at $37^{\circ} \mathrm{C}$. Hematoxylin (Gill No. 3; Sigma Immunochemicals) counterstain was added for $10 \mathrm{~min}$ at room temperature.

Morphometric analysis. Morphometric measurements of intimal and medial thickness were performed, and an intimal to medial ratio was determined in a blinded manner (Christian C. Haudenschild). Three ring segments from each transfected vessel were embedded in paraffin and sectioned at $4 \mu \mathrm{m}$ thickness for hematoxylin-eosin staining. The slides were projected onto the magnetic tablet of a manually operated tracing system (MOP; Carl Zeiss, Inc., Thornwood, NY) at approximately 100 -magnification. The luminal border, intima-media border and media-adventitia border were traced. The average intimal and medial thickness from each ring segment was measured, and an average intimal to medial ratio was determined for each vessel. Intimal to medial ratios were expressed as a mean \pm SEM. Comparisons between arteries transfected with the E. coli $\beta$-galactosidase reporter gene and the PDGF B gene were made by two-tailed unpaired $t$ test. Statistical significance was assumed if a null hypothesis could be rejected at the 0.05 probability level.

\section{Results}

To investigate the biological effects of the recombinant PDGF B gene in vivo, the expression vector plasmid was transfected into porcine iliofemoral arteries. Conditions for direct arterial gene transfer of the recombinant PDGF B gene into porcine iliofemoral arteries were established that minimized vessel injury. In order to determine an instillation pressure of the DNA liposome solution that did not injure the vessel wall, double balloon catheters (USCI, Billerica, MA) were positioned in the right and left iliofemoral arteries of two Yorkshire pigs. Phosphate buffered saline was instilled into the central space of the catheter into the left iliofemoral artery at $150 \mathrm{mmHg}$ and into the right iliofemoral artery at $350 \mathrm{mmHg}$ for $30 \mathrm{~min}$. Three weeks later, the vessels were fixed in situ with formalin at physiological distending pressures and analyzed by morphometry. Intimal and medial areas were measured, and intimal to medial area ratios were determined. Intimal hyperplasia was not observed in these iliofemoral arteries following instillation of saline at $150 \mathrm{mmHg}$, but, in contrast, intimal thickening was present following saline infusion at a higher pressure, 350 mmHg (Fig. $1 A$ vs. $B$ ). Measurements of intimal- to medialarea ratios revealed a significant difference between vessels instilled at $150 \mathrm{mmHg}$ and those instilled at $350 \mathrm{mmHg}$, $0.09 \pm 0.01$ vs. $0.26 \pm 0.04$, respectively $(P=0.005)$. In all subsequent gene transfer experiments, genetic material was instilled at $150 \mathrm{mmHg}$.

Three weeks following transfection of iliofemoral arteries, the presence of the plasmid encoding the recombinant PDGF $B$ gene was confirmed in transfected arteries using DNA PCR 

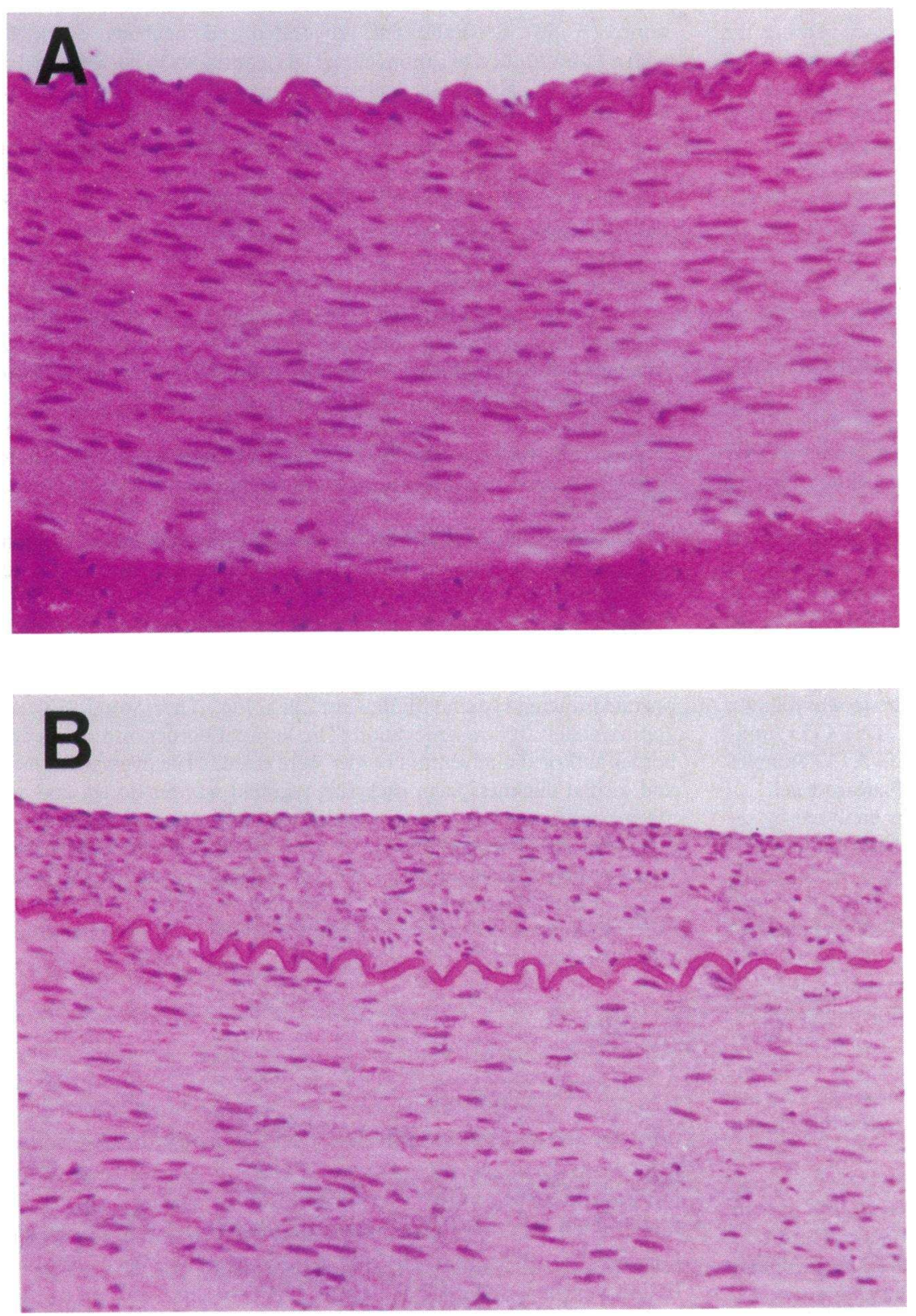

Figure 1. Light microscopy of balloon injured, nontransduced porcine iliofemoral arteries in vivo $21 \mathrm{~d}$ following infusion of saline into the central space of a double balloon catheter at $150 \mathrm{mmHg}(A)$ or $350 \mathrm{~mm} \mathrm{Hg}(B)$. Only the higher pressure, $350 \mathrm{mmHg}$, produced intimal thickening. $(\times 200$, hematoxylin-eosin stain $)$. analysis (Fig. 2). The recombinant PDGF B gene was detected in transfected right and left iliofemoral arterial segments (Fig. 2 , lanes 1 and 2) but not in nontransfected carotid arterial segments from the same pig (Fig. 2, lane 3), suggesting that gene transfer was limited to the site of introduction. Approximately 0.1 to $1 \%$ of cells in the artery segment were estimated to contain plasmid DNA by PCR approximation (data not shown); however, this estimate relies on the assumption that each cell contains a single plasmid. These results should, therefore, be interpreted with caution. Polymerase chain reaction analysis documented the presence of transduced plasmid DNA but does not show whether the recombinant gene is expressed. To confirm expression of the recombinant PDGF B gene, we analyzed transfected arteries for the presence of recombinant PDGF B mRNA by reverse transcriptase PCR. Using this technique, we readily detected recombinant PDGF $B$ mRNA in transduced arteries, in contrast to nontransduced arteries (Fig. 3, lanes 4 vs. 2) from the same animal.
Expression of recombinant PDGF BB protein was analyzed in transduced arterial segments by immunohistochemistry using a monoclonal antibody to human PDGF BB. Control pigs were transfected with a vector expressing $\beta$-galactosidase. No PDGF protein was detected by immunostaining in the intima or media, of arteries transfected with the E. coli $\beta$-galactosidase expression vector (Fig. $4 A-C$ ), indicating that the levels of endogenous protein in uninjured arteries transfected with a reporter gene at a low pressure $(150 \mathrm{mmHg})$ were below the level of detection. In contrast, porcine arteries transfected with the PDGF B gene at a low pressure $(150 \mathrm{mmHg}$ ) demonstrated immunoreactive protein in the intima, media, and adventitia (Fig. $4 D, E, F$ ). Cytoplasmic staining was present predominantly in the lumenal region of the intima. These data suggest that at a low transfection pressure used for all gene transfer experiments ( $\beta$-galactosidase and PDGF B genes), injury was not sufficient to detect endogenous PDGF protein with this antibody. Therefore, immunoreactive staining in PDGF B 


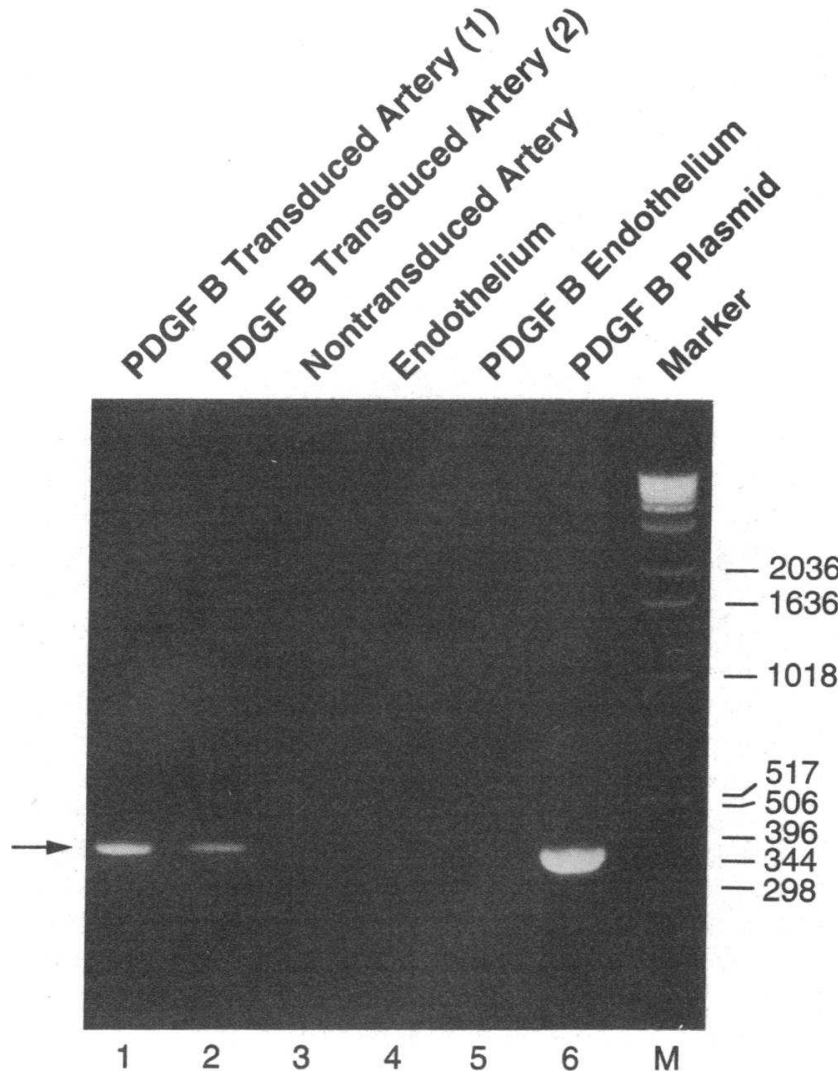

Figure 2. Expression of recombinant PDGF B gene by porcine arterial cells transduced in vivo and in vitro. The presence of recombinant PDGF B DNA in PDGF B gene transduced right (lane 1) and left (lane 2) iliofemoral arteries and nontransduced right carotid artery (lane 3) from the same pig $21 \mathrm{~d}$ following direct gene transfer, nontransduced porcine endothelial cells (lane 4), porcine endothelial cells stably transduced with the pSVL/PDGF B vector (lane 5), and PDGF plasmid control (lane 6) was determined by PCR.

gene transduced vessels must be recombinant protein, possibly in combination with endogenous protein produced in response to the recombinant PDGF B gene. Recombinant PDGF B gene expression was documented most definitively by the presence of its mRNA (Fig. 3).

We compared expression of recombinant PDGF BB protein with endogenous PDGF protein induced by balloon injury of nontransduced porcine arteries to determine the degree of vessel trauma necessary to detect endogenous PDGF protein. Nontransfected porcine arteries injured by balloon inflation $(500 \mathrm{mmHg}$ ) demonstrated PDGF immunoreactive protein in the intima and media (Fig. $4 G, H, I$ ). These data suggest that severe vessel injury, such as balloon inflation to $500 \mathrm{mmHg}$, will stimulate endogenous PDGF protein. In our gene transfer experiments, however, transfections were performed at a low pressure, and results in $\beta$-galactosidase transduced vessels suggest that the transfection procedure itself was not sufficient to provoke detectable levels of endogenous protein.

To determine whether macrophages could enter the transfected arteries to express recombinant PDGF protein, histochemical staining with a monoclonal antibody to porcine macrophages was performed. Macrophages in the intima were rarely detected in porcine arteries transduced with the PDGF B gene (Fig. $5 A, B, C$ ), and were not seen in E. coli $\beta$-galactosi- dase transduced arteries (Fig. 5 D) $7 \mathrm{~d}$ after direct gene transfer. In PDGF transfected vessels, the PDGF immunoreactive staining was mostly not associated with macrophages (Fig. $5 F$ ). These data suggest that macrophages may contribute some PDGF protein, but it is unlikely that the majority of the PDGF protein observed in the intima is synthesized by these rare cells. Similar observations were made using a nonspecific esterase stain for the macrophage (data not shown).

To evaluate the response of the arterial wall to expression of recombinant PDGF BB protein, the transfected artery segments were examined at $21 \mathrm{~d}$ by light microscopy. Arteries transduced with the PDGF B gene demonstrated intimal thickening in contrast to $\mathrm{E}$. coli $\beta$-galactosidase transduced arteries (Fig. 6, $A$ vs. $B$ ). Quantitative morphometry analysis of intimal and medial thickness revealed an eightfold greater intimalto-medial ratio in PDGF B gene transfected arteries compared with $\mathrm{E}$. coli $\beta$-galactosidase transduced vessels, $0.32 \pm 0.04$ vs. $0.04 \pm 0.01$, respectively $(P=0.001)$ (Fig. 7$)$.

\section{Discussion}

These results demonstrate that the expression of a recombinant PDGF B gene in normal arteries can induce intimal hyperplasia in vivo. PDGF has been implicated in many studies as a mitogen for mesenchymal cells in vitro (20). Recently, several studies have begun to address its biological function in vivo. Expression of PDGF B has been described in macrophages associated with atherosclerotic plaques (21). In addition, expression of PDGF B chain has been localized to the intimal region

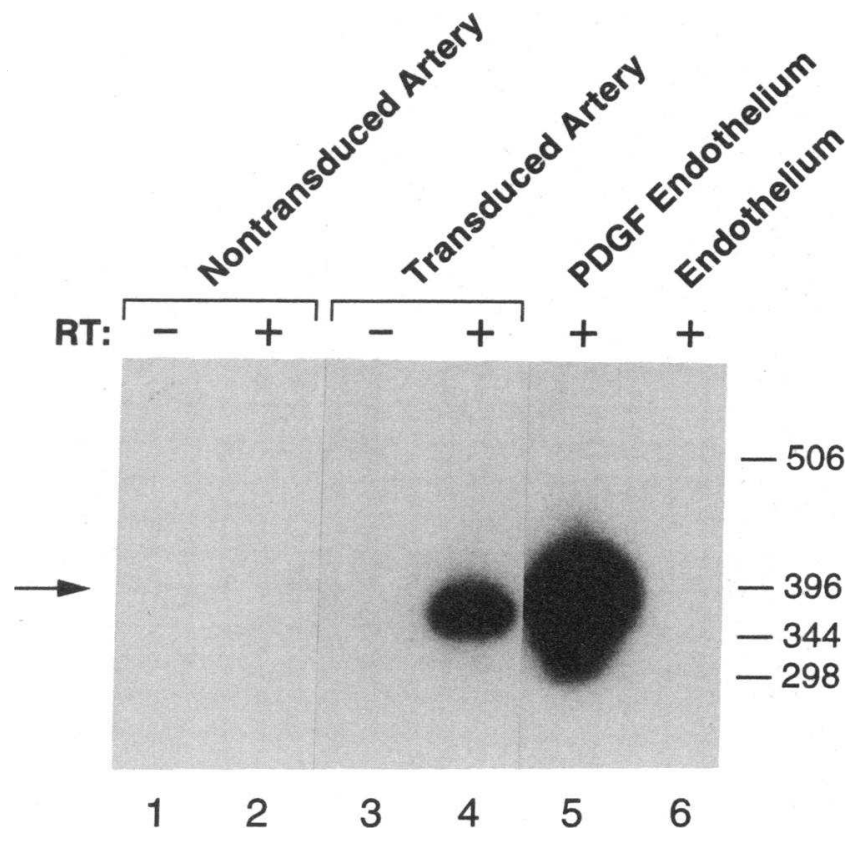

Figure 3. Expression of recombinant PDGF B mRNA in porcine cells in vitro and arteries in vivo. PCR was performed on mRNA from nontransduced carotid artery without (lane 1) or with (lane 2) reverse transcription; PDGF B gene transduced iliofemoral artery without (lane 3) or with (lane 4) reverse transcription; porcine endothelial cells stably transduced with the pSVL PDGF B expression vector (lane 5), and nontransduced porcine endothelial cells (lane 6 ) both after reverse transcription. RT, reverse transcription. 


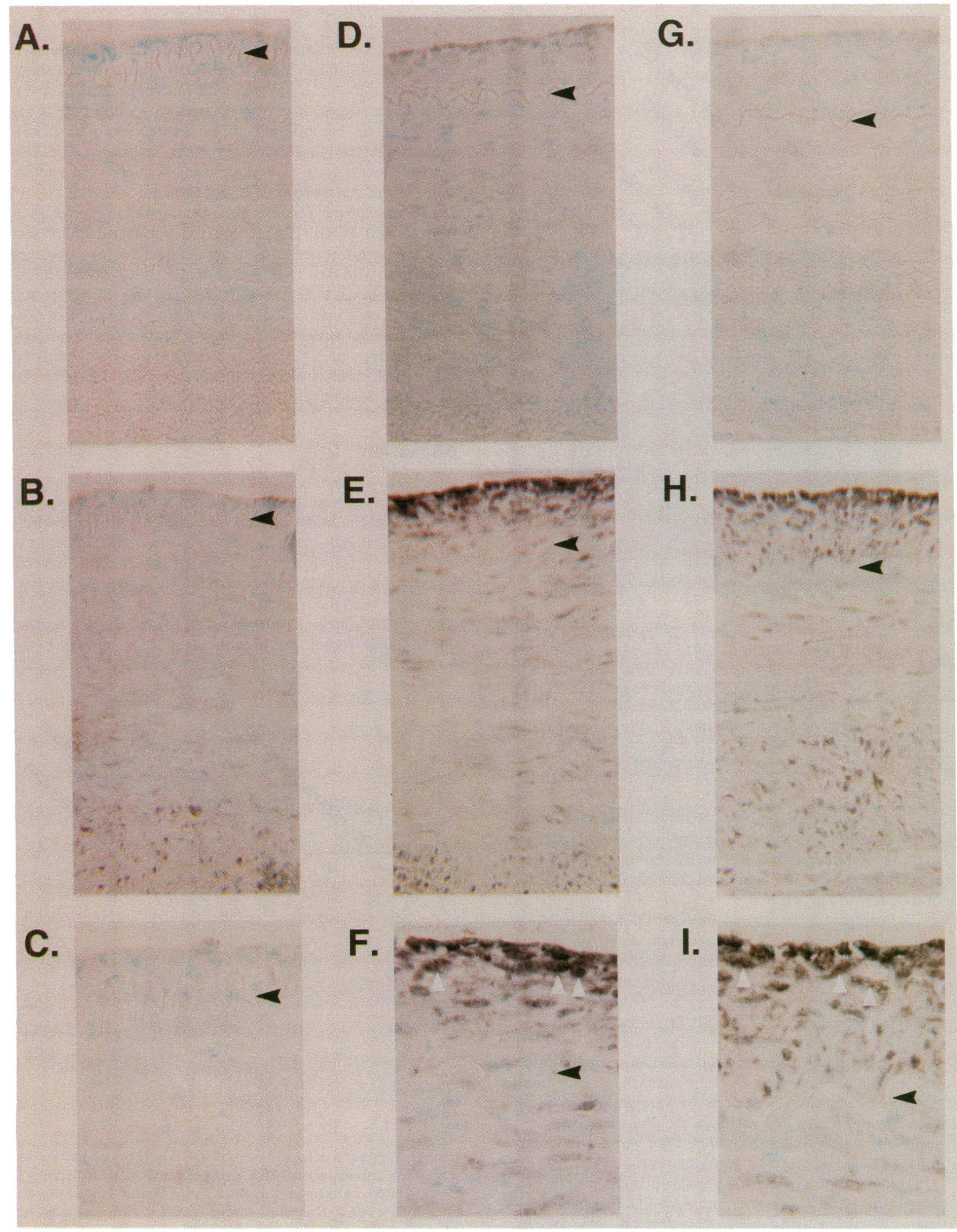

Figure 4. Expression of PDGF protein in porcine arteries in vivo. Porcine arteries transduced with a control gene, E. coli $\beta$-galactosidase $(A-C)$, demonstrated no PDGF immunostaining in the intima and media using a control antibody, purified $\operatorname{IgG}_{2 b}(A)$ or a monoclonal anti-human PDGF BB antibody $(B, C)$. In PDGF B gene transduced arteries $(D-F)$, immunostaining was absent using the control antibody $(D)$, but was 


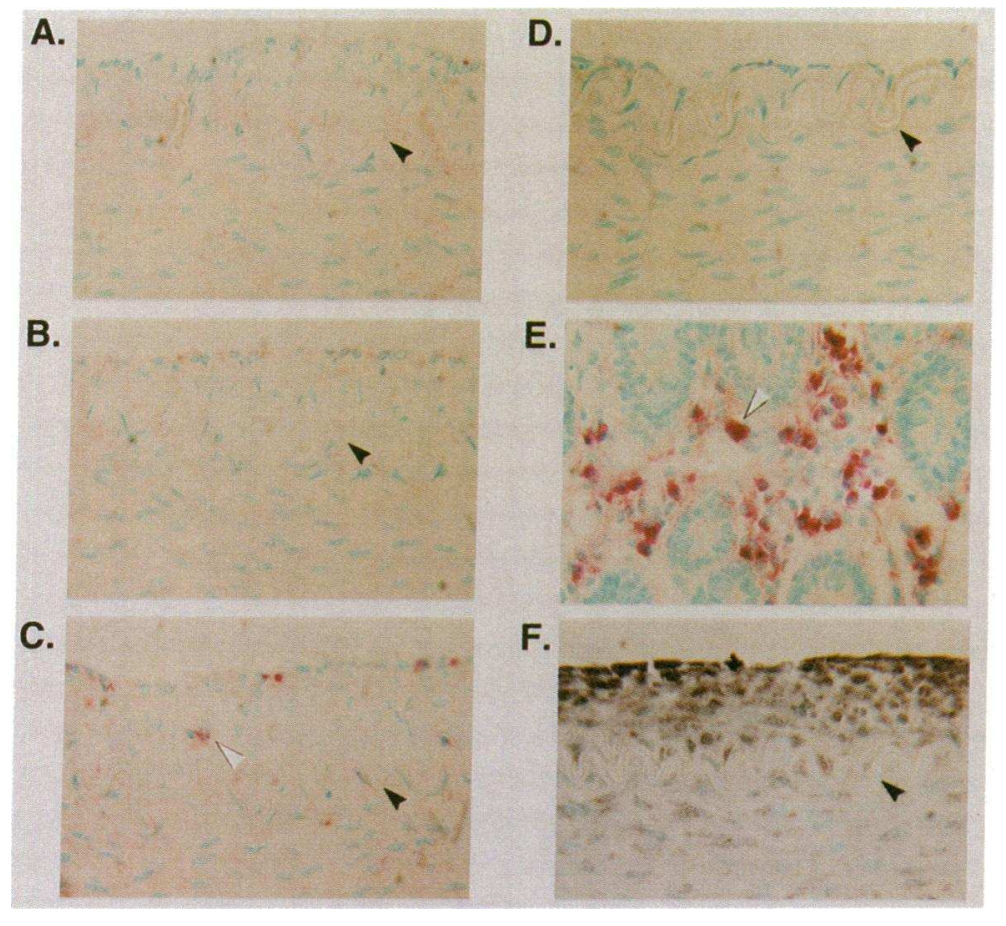

Figure 5. Immunohistochemical analysis of macrophages in porcine arteries in vivo. The presence of macrophages was determined in porcine arteries transduced with the PDGF B gene using a negative control, $\operatorname{IgG}_{2 \mathrm{~b}}$ antibody $(A)$, and a monoclonal $\operatorname{IgG}_{2 \mathrm{~b}}$ antibody to porcine macrophages $(B, C)$; in $\mathrm{E}$. coli $\beta$-galactosidase gene transduced arteries $(D)$; and in porcine intestine $(E)$. The occurrence of macrophages in $B$ and $C$ is contrasted with the extent of intimal PDGF immunoreactive protein $(F)$ in a PDGF B gene transduced artery at the same magnification. Black arrows denote the internal elastic lamina, and the white arrows denote macrophages. $(\times 364)$.

of the artery $(22,23)$. Functionally, the role of PDGF B has been assessed in several ways. PDGF protein infusions have increased intimal thickening in rat models of arterial injury (5). More recently, antibodies to PDGF have been shown to diminish the response to arterial injury (4). Despite these data, which associate PDGF with vascular proliferative responses, it has not been possible to show that PDGF B gene can (directly) induce intimal cell hyperplasia in the normal artery in vivo.

In these studies, we have examined the effects of recombinant PDGF $B$ gene expression in normal porcine arteries by analysis of DNA, mRNA, protein, and histology. The presence of plasmid DNA was documented using PCR, and recombinant gene expression was confirmed by mRNA studies. Immunostaining of endogenous PDGF protein was not observed in arteries transfected with the E. coli $\beta$-galactosidase gene, suggesting that at the instillation pressure $(150 \mathrm{mmHg})$ used in these experiments, endogenous PDGF protein was below the level of detection of the monoclonal anti-human PDGF antibody. Under the same conditions, recombinant PDGF protein was detected in PDGF B gene transduced arteries, and mRNA was detectable by PCR, suggesting that the recombinant gene was responsible for the intimal thickening observed by light microscopy. At the same time, it remains possible that endogenous PDGF protein was also produced in these PDGF B gene transduced arteries in response to the recombinant gene. Control experiments for the effects of mechanical injury alone using balloon injured, nontransfected arteries suggested that expression of endogenous protein was dependent upon the sever- ity of vessel injury and was not detected in vessels transduced at low pressures.

The mechanism by which PDGF is associated with intimal hyperplasia is not clear. Previous studies using $\left[{ }^{3} \mathrm{H}\right]$ thymidine labeling in rat carotid artery injury models have suggested that the effects of PDGF could not be accounted for by its mitogenic effects alone, raising the possibility that PDGF mediates its effect in part by stimulating migration of medial smooth muscle cells into the intima (4). Infusion of recombinant PDGF BB into rat carotid arteries following injury also increased intimal thickening primarily by migration of smooth muscle cells from the media to the intima (5). Separation of migration from proliferation in the rat balloon injury model is possible since uninjured rat artery contains no intimal smooth muscle cells. Because the uninjured pig intima may contain smooth muscle cells, it is difficult to determine whether PDGF is acting through migration, proliferation, or both of these mechanisms. In this large animal model, the $\left[{ }^{3} \mathrm{H}\right]$ thymidine and 5-bromo-2'-deoxyuridine labeling techniques used in smaller animals to dissect migration from proliferation are not readily adapted. However, the juxtalumenal localization of PDGF BB seen in the current study would be consistent with induced chemotactic effects on medial smooth muscle cells from the media to the intima and support a chemotactic role for PDGF BB in vivo.

Expression of the recombinant PDGF B gene may also stimulate the release of other endogenous growth factors in these arteries, and analysis of the expression of porcine growth fac- 

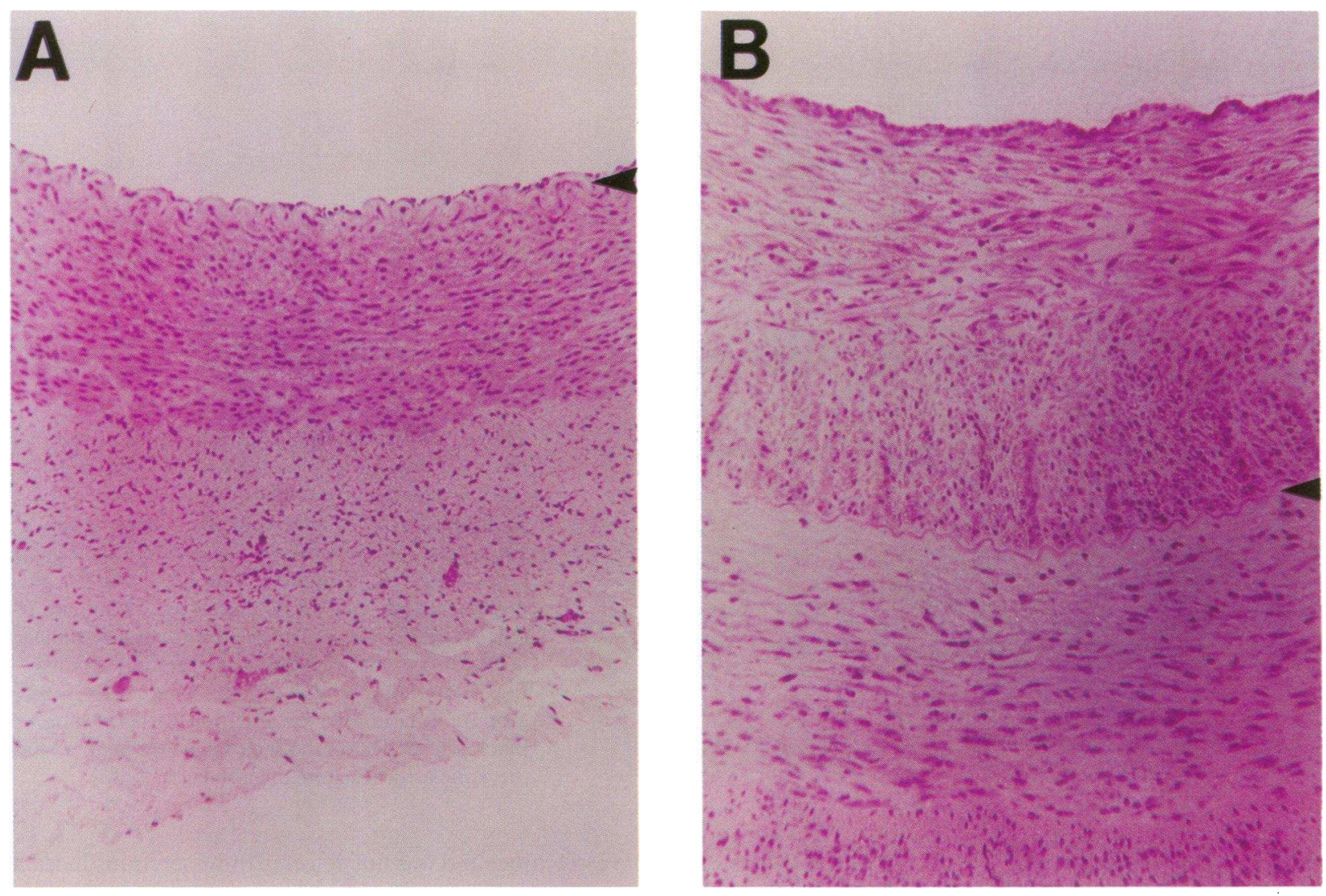

Figure 6. Light microscopy of transduced porcine arteries in vivo $21 \mathrm{~d}$ following direct gene transfer. Vessels were transduced with an $E$. coli $\beta$-galactosidase gene $(A)$ or a recombinant PDGF B gene $(B)$. The black arrows denote the internal elastic lamina. $(\times 100$, hematoxylin-eosin stain).

tors produced in response to recombinant PDGF BB synthesis are in progress. Localized synthesis of this gene product can therefore allow definition of other specific genes induced by individual growth regulatory proteins and may be useful in delineating the direct and indirect effects of PDGF gene expression. The current study suggests that expression of a recombinant PDGF B gene can produce intimal hyperplasia in normal porcine arteries. This model can serve as a prototype for examining the vascular phenotype induced by the expression of other recombinant growth factors, thrombolytic proteins or cellular adhesion molecules in the absence of arterial injury. It may also prove useful in the design of inhibitors of intimal hyperplasia to treat focal vascular diseases.

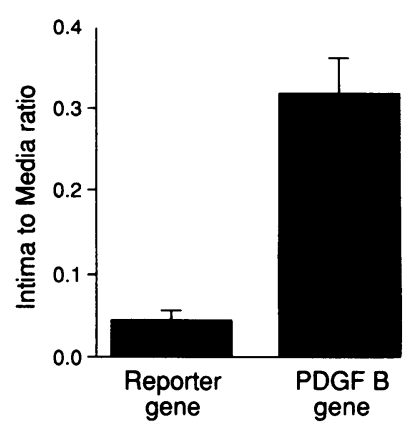

Figure 7. Analysis of intimal thickening in transduced porcine arteries in vivo $21 \mathrm{~d}$ following direct gene transfer. Intimal to medial ratios were determined for porcine arteries transduced with a control reporter gene $(n=6)$ and a PDGF B gene $(n=6)$. Values are expressed as a mean \pm SEM.

\section{Acknowledgments}

We are grateful to Russell Ross and Elaine Raines for comments and advice, to Lingling $\mathrm{Xu}$ for technical assistance, to Gail Reisdorph and Betty Plunkett for manuscript preparation, and to Dr. Brant Cochran, Massachusetts Institute of Technology for the PDGF B expression vector.

This work was supported by National Institutes of Health grants DK 42706, AI 29179, and HL 43757, and by American Heart Association grants 91012290 and 69CG912. Susanne Liptay was supported by a fellowship from the Deutsche Forschungsgemeinschaft.

\section{References}

1. Balk, S. D. 1971. Calcium as a regulator of the proliferation of normal, but not of transformed, chicken fibroblasts in a plasma-containing medium. Proc. Natl. Acad. Sci. USA. 68:271-275.

2. Ross, R., J. Glomset, B. Kariya, and L. Harker. 1974. A platelet-dependent serum factor that stimulates the proliferation of arterial smooth muscle cells in vitro. Proc. Natl. Acad. Sci. USA. 71:1207-1210.

3. Grotendorst, G., H. E. J. Seppa, H. K. Kleinman, and G. R. Martin. 1982. Attachment of smooth muscle cells to collagen and their migration toward platelet-derived growth factor. Proc. Natl. Acad. Sci. USA. 71:3669-3672.

4. Ferns, G. A. A., E. W. Raines, K. H. Sprugel, A. S. Motani, M. A. Reidy, and R. Ross. 1991. Inhibition of neointimal smooth muscle accumulation after angioplasty by an antibody to PDGF. Science. 253:1129-1132.

5. Jawien, A., D. F. Bowen-Pope, V. Lindner, S. M. Schwartz, and A. W. Clowes. 1992. Platelet-derived growth factor promotes smooth muscle migration and intimal thickening in a rat model of balloon angioplasty. J. Clin. Invest. 89:507-511. 
6. Nabel, E. G., G. Plautz, and G. J. Nabel. 1990. Site-specific gene expression in vivo by direct gene transfer into the arterial wall. Science. 249:1285-1288.

7. Lim, C. S., G. D. Chapman, R. S. Gammon, J. B. Muhlestein, R. P. Bauman, R. S. Stack, and J. L. Swain. 1991. Direct in vivo gene transfer into the coronary and peripheral vasculatures of the intact dog. Circulation. 83:20072011.

8. Leclerc, G., D. Gal, S. Takeshita, S. Nikol, L. Weir, and J. M. Isner. 1992. Percutaneous arterial gene transfer in a rabbit model. Efficiency in normal and balloon-dilated atherosclerotic arteries. J. Clin. Invest. 90:936-944.

9. Chapman, G. D., C. S. Lim, R. S. Gammon, S. C. Culp, S. Desper, R. P Bauman, J. L. Swain, and R. S. Stack. 1992. Gene transfer into coronary arteries of intact animals with a percutaneous balloon catheter. Circ. Res. 71:27-33.

10. Nabel, E. G., G. Plautz, and G. J. Nabel. 1992. Transduction of a foreign histocompatibility gene into the arterial wall induces vasculitis. Proc. Natl. Acad. Sci. USA. 89:5157-5161.

11. Lusky, M., and M. Botchan. 1981. Inhibition of SV40 replication in simian cells by specific pBR322DNA sequences. Nature (Lond.). 293:79-81.

12. Nabel, E. G., G. Plautz, F. M. Boyce, J. C. Stanley, and G. J. Nabel. 1989. Recombinant gene expression in vivo within endothelial cells of the arterial wall. Science. 244:1342-1344.

13. Stewart, M. J., G. E. Plautz, L. Del Buono, Z. Y. Yang, L. Xu, X. Gao, L. Huang, E. G. Nabel, and G. J. Nabel. 1992. Gene transfer in vivo with DNA-liposome complexes: safety and acute toxicity in mice. Hum. Gene Ther. 3:267-275.

14. Mosmann, T. 1983. Rapid colorimetric assay for cellular growth and survival: application to proliferation and cytotoxicity assays. Mol. Cell. Biol. 65:55-63.
15. Price, J., D. Turner, and C. Cepko. 1987. Lineage analysis in the vertebrate nervous system by retrovirus-mediated gene transfer. Proc. Natl. Acad. Sci. USA. 84:156-160.

16. Clowes, A. W., M. M. Clowes, and M. A. Reidy. 1986. Kinetics of cellular proliferation after arterial injury. Lab. Invest. 54:295-303.

17. Robbins, K. D., and S. A. Aaronson. 1988. The sis oncogene. In The Oncogene Handbook. E. P. Reddy, A. M. Skalka, and T. Curran, editors. Elsevier Science Publishers B. V., Amsterdam. 427-452.

18. Chomczynski, P., and N. Sacchi. 1987. Single-step method of RNA isolation by acid guanidinium thiocyanate-phenol chloroform extraction. Anal. Biochem. 162:156-159.

19. Sambrook, J., E. F. Fritsch, and T. Maniatis. 1989. Molecular Cloning: A Laboratory Manual. Cold Spring Harbor Laboratory, Cold Spring Harbor, NY.

20. Ross, R., E. W. Raines, and D. F. Bowen-Pope. 1986. The biology of platelet-derived growth factor. Cell. 46:155-169.

21. Ross, R., J. Masuda, E. W. Raines, A. M. Gown, S. Katsuda, M. Sasahara, L. T. Malden, H. Masuko, and H. Sato. 1990. Localization of PDGF-B protein in macrophages in all phases of atherogenesis. Science (Wash. DC). 248:10091012.

22. Wilcox, J. N., K. M. Smith, L. T. Williams, S. M. Schwartz, and D. Gordon. 1988. Platelet-derived growth factor mRNA detection in human atherosclerotic plaques by in situ hybridization. J. Clin. Invest. 82:1134-1143.

23. Gordon, D., M. A. Reidy, E. P. Benditt, and S. M. Schwartz. 1990. Cell proliferation in human coronary arteries. Proc. Natl. Acad. Sci. USA. 87:46004604. 